\title{
ASSESSMENT OF THE COMMUNICATIVE ABILITIES OF STUDENTS IN MEDICAL SPECIALTIES DURING THE ONLINE TRAINING PERIOD Monika Obreykova ${ }^{1}$
}

\begin{abstract}
:
Purpose: Communication skills are very important in the medical profession. Challenging for the teachers to develop the communication skills of future medical specialists through online classes during Covid-19.

Aim: To study the opinion of students about the importance of communication skills and its development through online classes during Covid-19, as well as to know the factors hindering the development of the communication process.

Materials and methods: A survey was conducted among 81 students in the field of "Health Care" majoring in "Nursing", "Midwifery" and "Medical Assisting" through a questionnaire. The data has been analyzed with the help of SPSS.

Conclusion: $67 \%$ of the students indicated that online learning will hamper the development of their much-needed communication skills to communicate with the patients. The results show difficulties in the implementation of quality health care which must be overcome. There is a need to improve the communication skills of the health care students by conducting special courses to overcome the deficiencies of online learning during Covid-19.

Communication skills are extremely important in the medical profession. It is challenging for teachers to develop the communication skills of future medical professionals through online classes during Covid-19. In the present study, students' opinion about the importance of communication skills and their acquisition during the pandemic through online classes, as well as the factors hindering the development of communication skills were studied. The present study reveals that most students majoring in nursing, midwifery and medical assisting lack communication skills, particularly in their communication with patients with disabilities. This problem is related to the flaws in the educational system for medical professionals, which prepares them to work in the real world.

It is established that a need for approbation and introduction of educational programs to develop the communication skills and to overcome the deficiencies of the online training during Covid-19 in this regard.
\end{abstract}

UDC Classification: 614.2, DOI: https://doi.org/10.12955/pmp.v2.184

Keywords: training, communication, students, Covid-19

\section{Introduction}

In recent years, attention has been paid to the clinical communication skills of medical professionals with patients with an emphasis on its positive effect as a cure. Communication is vital in all areas of health services, including prevention, care and education. Against the background of the growing trend for technology in medicine and the multicultural world, the need for an individualistic approach and personalized care for people based on their personal circumstances and needs (Andonova, 2017). The National Qualifications Framework in the Republic of Bulgaria defines knowledge, skills and four universal competencies as a result of training: independence and responsibility, competence for learning; communicative and social competencies; professional competencies (NQF, 2012). If future nurses want to provide the quality health care they must possess communication skills to communicate with their patients, their families and the multidisciplinary teams. Since communication is one of the main aspects of professional nursing, lack of communication skills can result in inefficient nursing duties (Terzieva 2012). Effective communication increases the level of a patient's satisfaction and trust in the medical professional. This helps the patient to calm down, reduce their fears and anxiety about the disease (Obreykova et al., 2020). On the other hand, communication failure can lead to more stress, misdiagnosis, it will also reduce patient's involvement in care plans and information sharing, which can lead to poor outcomes and even death. The concept of communicative competence among medical students specializing in health care can be defined as a complex of communicative knowledge, skills and abilities, medical, ethical and psychological knowledge, as well as personality traits, combined, integrated and manifested in daily communication with the patient and his relatives, colleagues, other medical and non-medical staff in work and non-work environment (Tacheva, 2014). Communication skills are of particular importance to the future medical professionals who are being trained electronically in the current situation of Covid-19. The training of medical students through online classes has a negative impact on the development of their communication skills for providing quality health care (Dragusheva 2015, Dragusheva et al., 2019). This highlights that due to e-learning the future medical professionals will not be successful in communicating with their patients and their respective families in a real environment. This is especially true for first year students who could not

\footnotetext{
${ }^{1}$ University Prof., “Dr Asen Zlatarov”, Departament of Health care, Burgas, Bulgaria, monika_obrejkova@abv.bg
} 
implement and practice their communication skills. In many countries around the world, the Covid-19 pandemic has caused major changes to prevent the virus spread. This has led to the closure of schools and universities, to maintain social distancing to prevent the spread of the virus. Students in 2020/21 were able to communicate with patients for a very short time due to the imposed emergency restrictions. They talked to patients superficially and communication was always about their physical well-being and little attention was paid to their psychological needs. Developing communication skills in medical professionals aims to solve communication problems. Expressing support in personal and interpersonal communication, helping patients to overcome anxiety are just some examples that future medical professionals will practice during treatment. Due to the covid-19 pandemic, teachers and students are facing the challenges of online learning. Improving the communication skills of future medical professionals is a priority for ensuring patient's safety, which will eliminate the weaknesses in this regard and provide an opportunity for planning the health care in the future. This research is an attempt to establish the level of communicative competence and skills of future medical professionals, as well as evaluation of online training; whether it provides opportunities to acquire these or not.

\section{Aim of the study}

The study aims to assess and analyze different communication skills in health care students. The objective of the research is to seek the opinion of future medical specialists about the importance of developing communication skills during online training. The scope of the research is a total of 81 students from the University "Prof. Dr. Asen Zlatarov" city of Burgas. Materials and methods of the research: Relevant literature on the topic has been analysed; the study is based on sociological and documentary research. Data has been collected through a survey. The collected data is statistically analyzed with the help of SPSS.

\section{Results and analysis}

To establish the level of communicative competence of the medical students in the field of health care, data has been analyzed with SPSS. Out of 81 students surveyed, 38 (47\%) were from "nursingO" specialty- 23 (28\%) from "midwifery", and 20 (25\%) from "medical assisting" were there. Specialization wise distribution of the respondents is presented in Fig.1

\begin{tabular}{|r|r|}
\hline Figure 1: What is your specialty? \\
\hline physician assistant & $25 \%$ \\
midwife & $28 \%$ \\
nurse & $47 \%$ \\
\hline Source: Author & \\
\hline
\end{tabular}

Effective communication requires the right use of verbal signals and this requires the ability to "hear" and "listen". Man is born with the ability to hear, but listening requires skills to interpret and decode what is heard. And this can be developed through proper training, which future medical professionals undergo in medical schools. It is assumed that students must develop and apply "empathic listening", which will allow them to understand and empathize with their patients.

To the question "Determine the degree of importance of communicative competence in students during Covid-19" 30\% of the respondents gave a high degree of importance to communicative competence, while $43 \%$ gave it medium importance, $7 \%$ rated it as low and for $1 \%$ of the respondents it has no significance. The results outlined that the majority of the students gave high importance to the communication skills. Most medical students need additional training to develop their communication skills, especially during Covid 19 (Figure 2):

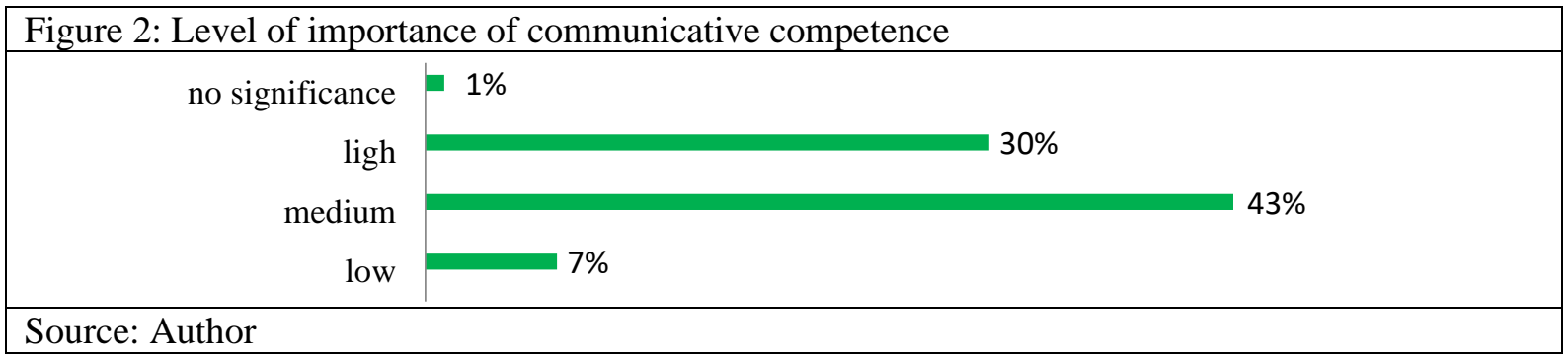


Many factors including education level, circumstances in life, number of siblings, and training experience have a significant impact on the communication skills of future health care professionals. Therefore, we logically asked the next question "on which factors does communication competence depends?". $68 \%$ of the respondents quite reasonably pointed "lack of knowledge of the medical specialist regarding communication skills", $57 \%$ of the respondents attributed it to " lack of practical skills", this is indicating towards insufficient communication skills. $42 \%$ of the respondents reported "conversational and language difficulties between patient and medical professionals", this highlights the deficiencies in medical specialties caused by e-learning. The need to develop the communication skills that underlie health care has become clear. Quite rightly, 30\%, students marked that the state of emergency and the inability to conduct practical exercises affect the development of communication skills and their ability to adapt more easily to the hospital environment. This result outlined the difficulties faced by the future health professional, namely the lack of sufficient experience in a real environment. Students indicate as a significant factor "lack of sufficient time of the medical specialist", $35 \%$ of the respondents attributed their low level of communicative competence to insufficient time to practice it. 95\% of the respondents indicated "the use of protective materials (masks, face shields)" a reason for ineffective communication with patients. $14 \%$ of the students cited "differences in the age of the medical patient", $12 \%$ responded that "low self-esteem of the medical professional" and $11 \%$ said "gender differences between patient and medical professionals". While $7 \%$ of the respondents believed that the obstacles described above do not hinder their communication process (Fig. 3):

Figure 3: Factors on which communicative competence depends

Do not consider that obstacled described above interfere the communication process

Due to the lack of practical skills

Due to onlain training

The presence of protective materials (mask, helmets)

Lack of sufficient time of the medical specialist

Conversational language difficulties between a patient and the medical specialist

Low self-esteem of the medical specialist

Lack of knowledge of the medical specialist regarding to communication skills

Gender differences between patient and medical specialist

Differences in age between the patient and the medical specialist

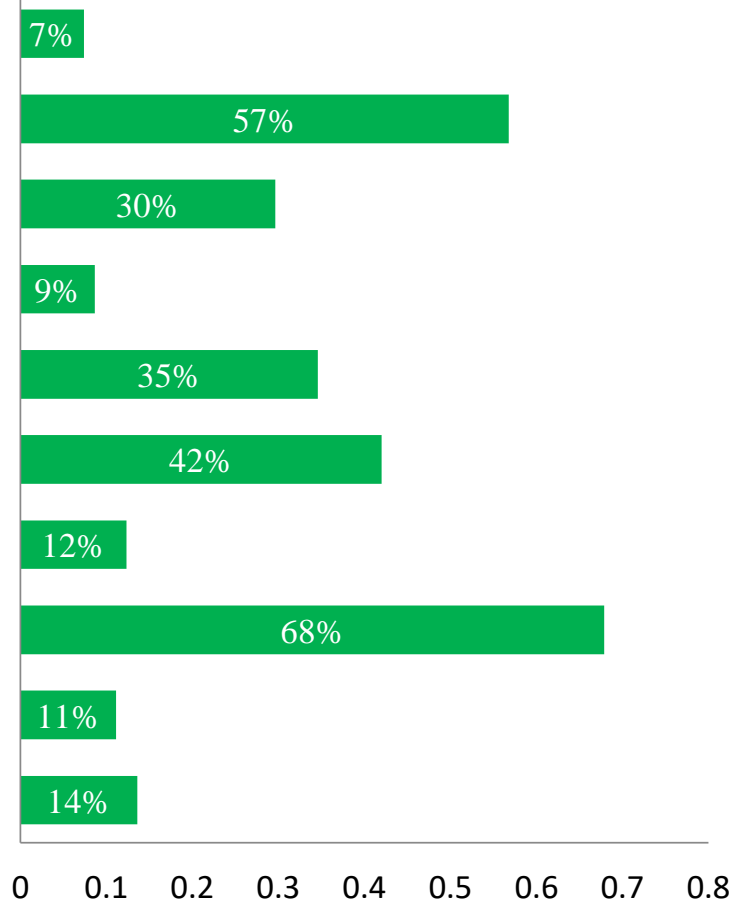

\section{Source: Author}

The study finds that $36 \%$ of the students attributed the current pandemic (environment) as the biggest communication barrier, particularly the restrictions imposed during the Covid-19 pandemic. $21 \%$ of students stated that communication barriers are related to the medical professionals that affect the sufficient development of knowledge and skills related to communicative competence. $16 \%$ of respondents said the communication barriers are related to the patients, as they are afraid to communicate with their health care providers. While as per the $27 \%$ of future "medical professionals" there are no communication barriers, this instils confidence in them that they will deal with the problems. 


\begin{tabular}{|l|}
\hline Figure 4: Barriers in the communication \\
\hline I,don't think there are barriers \\
Yes, related to environment \\
Yes, related to medical professionals \\
Yes, related to the patient \\
\\
Source: Author
\end{tabular}

To determine the skills required for a quality communication process, the students were asked "Which skills do you think are needed to conduct a good communication process?". To provide quality medical care, it is necessary for the specialists to use communication skills to extract the most important information about the patient's health condition. These skills will facilitate the communication process and will allow students to perform well in e-classes. $74 \%$ of the respondents stated that "active listening skills" are required for good communication, $65 \%$ of the respondents said it is "questioning skills" and 51\% responded that "skills during the communication" are required for good communication. The responses reveal the need to develop their communication skills. Next, 59\% of the respondents stated that it is "communication skills in accordance with the difficulties in communication of patients with disabilities". This finding highlights the need for better communication skills given the limitations of online learning and the lack of regular practical training in a real hospital environment. $43 \%$ of future healthcare professionals surveyed pointed to "knowledge and skills for patients with disabilities" as an important skill for effective communication process, which emphasizes the need to enhance their communication skills. According to $35 \%$ of the students "public communication skills" is required, $19 \%$ of them said it is the "presentation skills" and $37 \%$ of the students responded that "personal communication skills with the patient" is required for good

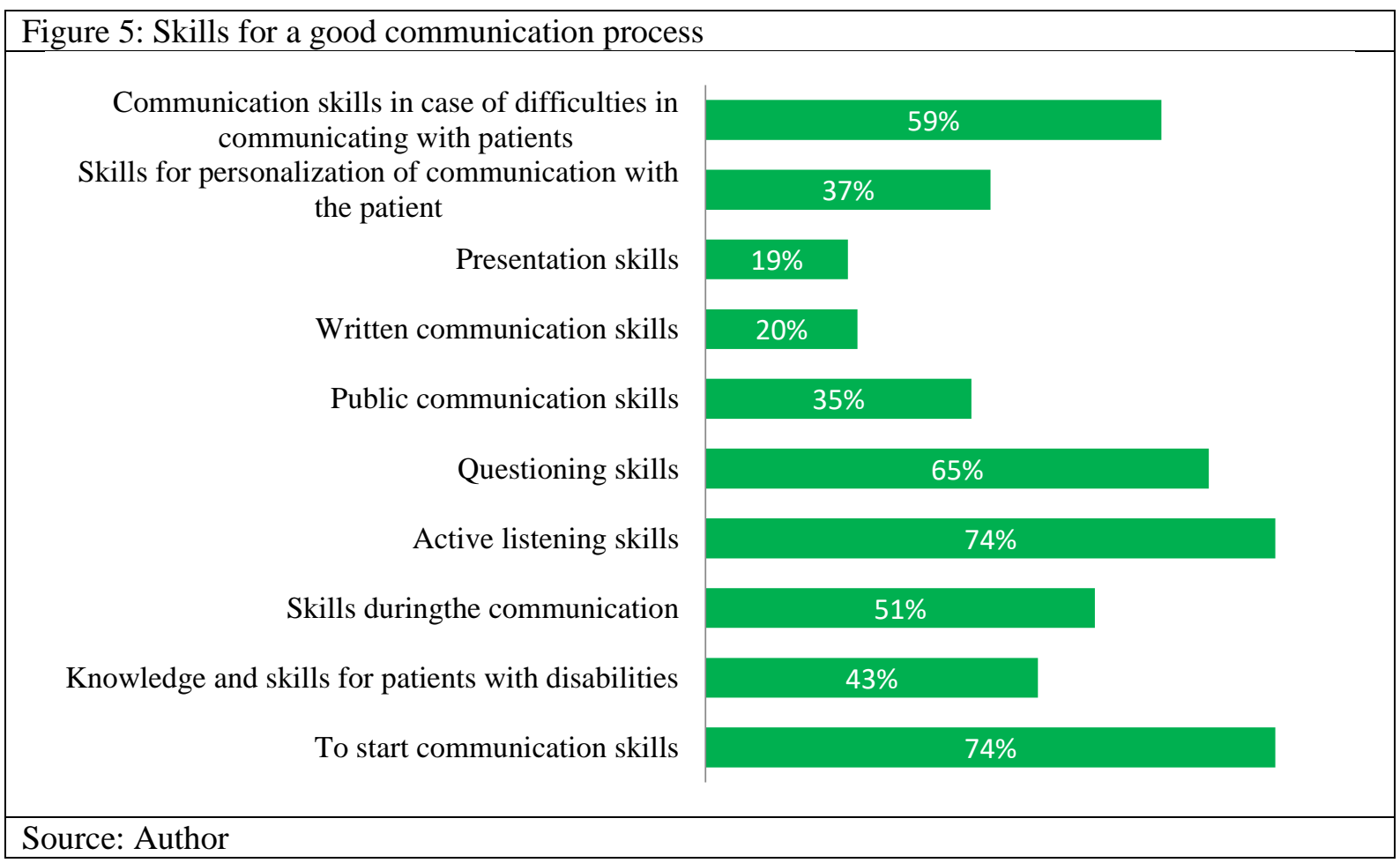

communication process. The acquisition of these skills would allow them to build confidence to communicate effectively in their profession. $20 \%$ of the respondents indicated that "written communication skills" is important to practice their profession competently (Fig. 5).

Due to Covid-19, a shift towards online classes has a negative impact on training at medical schools. This problem raised the following question: "Does digital learning allow students to prepare and 
develop communication skills that ensure proper communication with patients?". From the responses, it has been found that students are apprehensive about the quality of education in an online mode. $67 \%$ of the students responded that that digital learning will not allow them to develop much-needed communication skills to communicate with the patient. Only $11 \%$ of respondents believed that they would receive adequate training, while $22 \%$ of the students said that they "cannot judge" the pros or cons of digital learning.

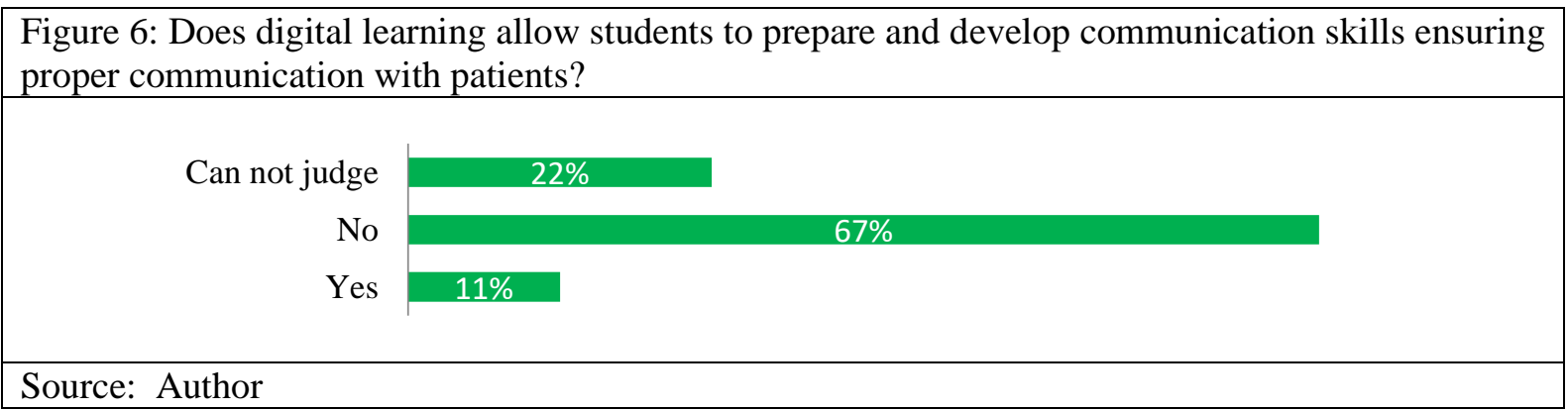

Our study suggests the need for realization of a communication course or an enhanced clinical communication training to improve nurses' communication skills during online training. That is why the next question was asked: "How do you rate the innovations in training?". 37\%, the respondents rated them as "bad" while $25 \%$ rated them as "satisfactory". Based on these findings, it can be concluded that students do not prefer online learning, especially for developing their communication skills. Sufficient communication skills cannot be developed online, which will further make it difficult for them to have effective communication with patients, doctors, nurses, laboratory technicians and other specialists in the health sector. Only $4 \%$ of the surveyed students indicated it as "excellent" and $15 \%$ rated these as "good" innovations in online learning, due to covid-19. Based on the responses of the students it can be stated that online training in medical specialties is unsuccessful and leads to certain shortcomings and hindering the implementation of adequate health care. Quite logically, another question was asked about the need for conducting up-to-date training to develop communication techniques to provide better health care services. $90 \%$ of the respondents stated a desire to include such training, that will help them to provide better health care.

\section{Conclusion}

The study concludes that the main difficulty faced by students while working with patients is in the lack of communication skills due to unexplored communication techniques in health care. Other significant difficulties are related to the insufficiency of knowledge acquired through online classes during the pandemic and the lack of communication with patients. It has also been found that students want to join an additional program for developing their communication skills to communicate effectively with adult patients and patients with disabilities. The need for the approbation of a program for introducing communication techniques to enhance the quality of health care has been identified.

Students clearly outlined the need for improved communication skills that are the foundation of health care. Respondents highly valued communication skills. Most medical students need additional training to develop their communication skills, especially during Covid-19. Students believe that communication skills are very important in their profession and the respondents feel they lack communication skills. Students strongly believed that the present situation of e-learning due to the pandemic is responsible for the deterioration of the quality in education. They indicated that digital learning is restricting their ability to develop much-needed communication skills to communicate effectively with the patient. The covid-19 challenge and the subsequent e-learning deprived the health care students from developing quality communication skills. The imposed restrictions outlined the need for additional training to improve the communication skills of future healthcare professionals to provide quality health care. The present research outlines the findings that students lack knowledge and skills related to their communicative abilities to communicate effectively with their patients. The students expressed their opinion about the inclusion of new educational programs for developing communication skills especially to communicate with patients with disabilities. This problem is related to the updating of the course content to prepare the medical specialists for working in a real 
environment. Therefore, it is recommended to introduce new programs to develop communication skills and to make up for the deficiencies of the online learning.

\section{References}

Andonova, A. (2017). The Importance of Effective Communication in Medical Practice. In: Academic Journal Management and Education, Burgas, v. XIII (5), pp. 9-12, http://www.conference-burgas.com/maevolumes/vol13/b5_v13.pdf

Dragusheva S. (2015). The need to from communication skills in future nurses. Monografia wieloautorska. Komunikacja w edukacji dzieci,młodzieży i dorosłych. 2015; 122-127, ISBN 978-83-941235-4-3

Dragusheva S., P. Petleshkova, G. Panova (2019)- Incentives motivating mentors and criteria forselecting mentors in the pregraduation traineeship of future registered nurses. Macedonia Journal of Medical Sciences,Skopje; Okt15; 7(19):3294-3279; eISSN:1857-9655; https://doi.org/10.3889/oamjms.2019.714

NQF (2012). The National Qualifications Framework in Bulgaria, adopted by PMS №96/02.02 2012. https://eacea.ec.europa.eu/national-policies/eurydice/content/national-qualifications-framework-12_bg

Obreykova M., A. Andonova, Galina Terziva (2020) Increasing the Competencies of Nurses Working With Children With Disabilities in the Transition From Institutional to Deinstitutional Care Management and education, Vol. XIII (5), vol.16 (5), pp.113-121. http://www.conference-burgas.com/maevolumes/vol16/b5_v16.pdf

Tacheva V., (2014). Communication skills in medical practice”, ISBN978-954-449-797, Varna

Terzieva, G. (2012). Upravlenie kommunikatsiyami v sisteme prepodavately - stazhor - nastavnik stazhora - patsient [Communication management in the system theacher-traine-theacher traine-patient]. B: Kompetencje wspólczesnego nauczyciela, t. II, pp. 304-308, Siedlce, Polska. ISBN 978-83-934036-9-1. 